\title{
The changing of silicon suboxide film thickness as a result of high temperature annealing
}

\author{
Alexandr Zamchiy ${ }^{1,2, *}$, Evgeniy Baranov ${ }^{1}$ \\ ${ }^{1}$ Kutateladze Institute of Thermophysics SB RAS, 630090 Ac. Lavrentiev ave. 1, Novosibirsk, Russia \\ ${ }^{2}$ Novosibirsk State University, 630090 Pirogova str. 2, Novosibirsk, Russia
}

\begin{abstract}
The $\mathrm{a}-\mathrm{SiO}_{\mathrm{x}}: \mathrm{H}$ thin films were deposited by the gas-jet electron beam plasma chemical vapor deposition method with different stoichiometry $(x=0.15-1.0)$ for different $\mathrm{SiH}_{4}$ flow rates. The concentration of hydrogen in the films increases with the growth rate in ranges from 1.5 to 4.8 at.\%. Further annealing leads to the effusion of hydrogen from the structure of the material and the compression of the structure, which leads to a reduction in the thickness for all films. X-ray diffraction measurements showed that the as-deposited films crystallized to form nc-Si about 4-8 nm in size after annealing at $1000^{\circ} \mathrm{C}$.
\end{abstract}

\section{Introduction}

Low-dimensional silicon systems have higher light-emitting effects, which can be a potential source for the realization of silicon based optoelectronic devices [1]. Typical features of silicon nanomaterials are excellent properties, due to the large surface-tonanocluster volume ratio. At the present time, various nanostructured silicon materials are intensively studied, for example, nanocrystalline silicon embedded in a silicon oxide matrix.

There are two main ways to produce nanocrystalline silicon in a silicon oxide matrix. The first method is direct synthesis of nc-Si (nanocrystalline silicon) films, for example, by chemical vapor deposition in a single-step process $[2,3]$. But this method requires a high deposition temperature and it is difficult to control the crystallite size and the degree of crystallinity. The second method is to obtain nanocrystalline silicon in a silicon oxide matrix in two stages; in the first stage, a film of amorphous silicon suboxide of not high purity is formed, in the second stage the film is crystallized. The following methods are used for the crystallization process: solid-state crystallization [4]; rapid thermal annealing [5]; metal-induced crystallization [6].

Sometimes, to reduce the thermal budget, joint use of various annealing options, for example rapid thermal annealing and annealing in a tube furnace [7] is used. Another option is annealing at low temperature to form nuclei and amorphous clusters and postannealing at a higher temperature for the crystallization of clusters and the growth of crystallites. To obtain ncl-Si (silicon nanoclusters) in a silicon oxide matrix, a temperature of between $600^{\circ} \mathrm{C}$ and $800^{\circ} \mathrm{C}$. is usually used when phase separation of excess silicon

* Corresponding author: zamchiy@gmail.com 
occurs, creating amorphous silicon nanoclusters surrounded by an amorphous silica matrix. Post-annealing at temperatures above $900^{\circ} \mathrm{C}$ leads to the crystallization of these amorphous nanoclusters.

In this work, $\mathrm{a}-\mathrm{SiO}_{\mathrm{x}}: \mathrm{H}$ thin films were deposited by the gas-jet electron beam plasma chemical vapor deposition (GJ EBP CVD) method with different stoichiometry. Then, the samples were subjected to a standard annealing procedure for 8 hours at $700^{\circ} \mathrm{C}$ and then for $12 \mathrm{~h}$ at $1000^{\circ} \mathrm{C}$ in $\mathrm{Ar}$ atmosphere in a quartz tube. The effect of following annealing at different temperatures on the thickness and structure of amorphous hydrogenated silicon suboxide thin films was studied.

\section{Experimental details}

In this work, $\mathrm{a}-\mathrm{SiO}_{\mathrm{x}}: \mathrm{H}$ thin films were obtained by the GJ EBP CVD method. A detailed description of the method can be found in [8]. The thin films were obtained for different $\mathrm{SiH}_{4}$ flow rates $(4.45 ; 3.56 ; 2.67 ; 1.78$ and $0.89 \mathrm{sccm})$ at the constant Ar flow rate of 330 sccm. In addition, oxygen was supplied into the vacuum chamber through a leak valve at a flow rate of $5 \mathrm{sccm}$ throughout the experiment. The substrate temperature was $260^{\circ} \mathrm{C}$ during the synthesis. The deposition time was varied from 7 to $35 \mathrm{~min}$ in order that the samples had a thickness more than $500 \mathrm{~nm}$. The substrates were $\mathrm{c}-\mathrm{Si}<100>$ wafers.

The samples were subjected to a standard annealing procedure for 8 hours at $700^{\circ} \mathrm{C}$ and then for 12 hours at $1000^{\circ} \mathrm{C}$ in Ar atmosphere in a quartz tube. Preliminary, the samples were annealed at $450^{\circ} \mathrm{C}$ for 1 hour for slow and non-destructive effusion of hydrogen from the $\mathrm{a}-\mathrm{SiO}_{\mathrm{x}}: \mathrm{H}$ thin films.

Raman spectroscopy was used to investigate the structure of the as-deposited films. Raman spectra were recorded with a Horiba Jobin Yvon T64000 spectrometer using the $514 \mathrm{~nm}$ line of an $\mathrm{Ar}^{+}$laser as the exciting source.

Investigations of post-annealed samples were carried out at time resolved diffractometry station (channel 5b, VEPP-3) of the Siberian Synchrotron and Terahertz Radiation Center [9]. An OD-3M position-sensitive detector was used in the conventional experimental setup with a wavelength $1.516 \AA$ [10]. The detector was positioned at an angle of $25^{\circ}-56^{\circ}$ to record the main silicon peaks. The acquisition time was $20 \mathrm{~min}$. After intensity normalization, the signal of the empty substrate was eliminated from the signal of the sample.

The thickness of as-deposited and annealed films was investigated by Fourier transform infrared (FTIR) spectroscopy. IR spectra of the samples were measured by Bruker IFS-113V Fourier spectrometer in the range of $4000-400 \mathrm{~cm}^{-1}$ with a $1 \mathrm{~cm}^{-1}$ resolution. The measurements were conducted in the transmission mode with normal incidence of radiation on the substrate. The substrate area without a film was used as a reference to avoid the influence of the c-Si substrate and its native oxide film during the measurements. The absorption spectra of the studied thin films were obtained by subtracting the absorption spectrum of the reference from the total signal. The thickness of as-deposited and annealed $\mathrm{a}-\mathrm{SiO}_{\mathrm{x}}: \mathrm{H}$ thin films were determined from the analysis of the transmission spectra in the infrared range, from the peaks of interference [11].

\section{Results and Discussion}

It is well known from the literature that the properties and structure of the material after annealing are determined by characteristics of as-deposited films. The growth rate of asdeposited films increases $(0.4 \div 1.4 \mathrm{~nm} / \mathrm{s})$ with increase in flow rate of monosilane, which is a direct consequence of the increase in the number of radicals of silicon in electron-beam 
plasma. It should be noted that the increase in the rate of growth is not linear and tends to saturate.

In the as-deposited films, the oxygen concentration decreases from 50 to 12 at.\% with increasing growth rate [12]. Most likely, the reaction rate of the oxidation of one monolayer in the synthesis process of the film is a constant. The hydrogen concentration has a reverse tendency i.e. the hydrogen concentration increases from 1.5 to 4.8 at.\%. But it should be noted that the flow of oxygen to the substrate surface has a constant value, while the flow of hydrogen atoms increases in proportion to the increase of $\mathrm{SiH} 4$ flow rate.

Raman spectra of as-deposited thin films shows that the films are amorphous. The Raman spectra of all other films also exhibit similar features.

The annealing of the as-deposited silicon suboxide thin films was carried out in two stages. All samples were annealed at $700^{\circ} \mathrm{C}$ for 8 hours on first stage, and then at $1000^{\circ} \mathrm{C}$ for 12 hours on second stage.

Annealing at $700^{\circ} \mathrm{C}$ did not lead to the formation of nanocrystalline silicon in the silicon suboxide matrix. According to the literature data [13], amorphous nanoclusters in the silicon oxide matrix are formed at this annealing temperature. And the formation of nanoclusters and crystallites depends significantly on the concentration of oxygen in the asdeposited films. The formation of nanoclusters and nanocrystals occurs at lower temperatures for a lower oxygen concentration.

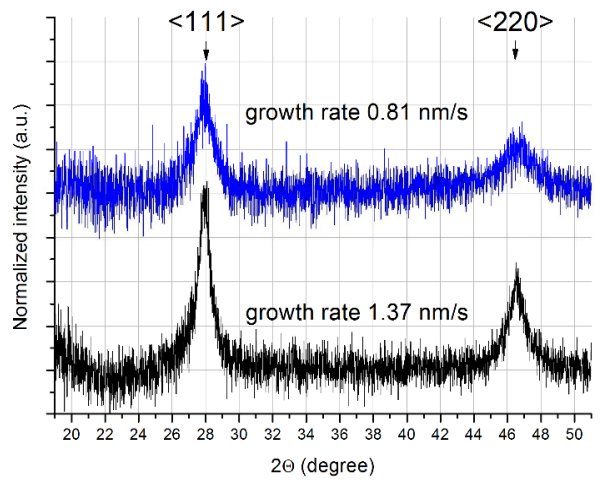

a

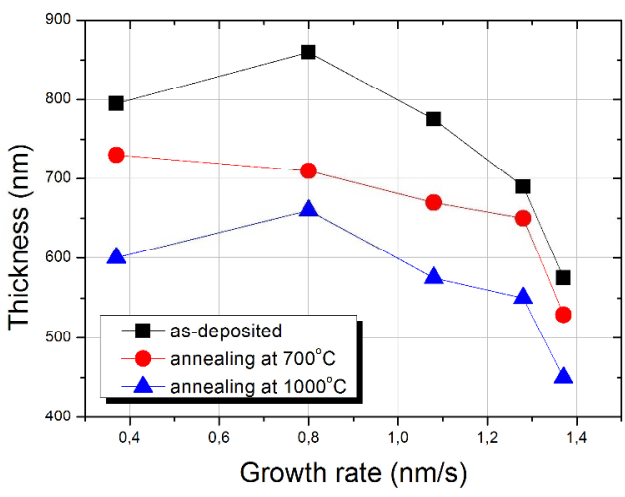

b

Fig. 1. a) The XRD spectra of the samples after annealing at a temperature of $700^{\circ} \mathrm{C}$ for $8 \mathrm{~h}$ and $1000^{\circ} \mathrm{C}$ for $12 \mathrm{~h}$. The growth rate of the films is shown in the spectra; b) Variations of thickness of asdeposited and annealing films with respect to the $\mathrm{SiH}_{4}$ flow rate.

Post-annealing at $1000^{\circ} \mathrm{C}$ for 12 hours resulted in crystallization of amorphous silicon clusters in the silicon suboxide matrix [14]. As a result of annealing, crystallites of nanometer size were formed. For example, the XRD pattern for annealed films obtained at a growth rate of 0.8 and $1.37 \mathrm{~nm} / \mathrm{s}$ is given in Fig. 1a. It can be seen from the figure that the two peaks corresponding to $<111>$ and $<220>$ of the Si crystallographic orientation were identified at $28^{\circ}$ and $46.5^{\circ}$, respectively. The ratio of the intensity of peak $\langle 111\rangle$ to the intensity of peak $<220>$ is close to the standard reflections of c-Si. This suggests that the nanocrystallites of silicon in the suboxide matrix have a nearly spherical shape. According to the crystallite size determination method described in [15], the crystallite size was 4-8 $\mathrm{nm}$ for the samples obtained in this work.

The low porosity had an effect on the thickness of the films during annealing. The data on the change in the film thickness as a function of the growth rate and annealed at a temperature of $700{ }^{\circ} \mathrm{C}$ and $1000^{\circ} \mathrm{C}$ are shown in Fig. 1b. As a result of annealing, the thickness of the films decreases for all samples. This indicates that the as-deposited films 
have a high porosity. During annealing, intensive oxidation of a film having a developed surface due to a porous structure takes place, while the number of pores decreases as a result of effusion of hydrogen and the healing of defects.

Further annealing leads to the effusion of hydrogen from the structure of the material and the compression of the structure, which leads to a reduction in the thickness for all films.

\section{References}

1. H. Liu, Y. Yang, J. Liu, Z. Jiang, Y. Li, W. Yu, W. Ding, G. Fu, J. Alloys Compd. 671 (2016)

2. A. Samanta, D. Das, J. Mater. Chem. C. 1 (2013)

3. J.A.L. López, J.C. López, D.E.V. Valerdi, G.G. Salgado, T. Díaz-Becerril, A.P. Pedraza, F.J.F. Gracia, Nanoscale Res. Lett. 7 (2012)

4. A. Coyopol, M.A. Cardona, T.D. Becerril, L. Licea Jimenez, A.M. Sánchez, J. Lumin. 176 (2016)

5. W. Zhang, S. Zhang, Y. Liu, T. Chen, J. Cryst. Growth. 5 (2009)

6. A.O. Zamchiy, E.A. Baranov, S.Ya. Khmel, V.A. Volodin, V.I. Vdovin, and A.K. Gutakovskii, 124 (2018)

7. D. Hiller, S. Goetze, M. Zacharias, J. Appl. Phys. 109 (2011)

8. E.A. Baranov, S.Y. Khmel, A.O. Zamchiy, IEEE Trans. Plasma Sci. 42 (2014)

9. O.V. Evdokov, V.M. Titov, B.P. Tolochko, M.R. Sharafutdinov, Nucl. Instruments Methods Phys. Res. Sect. A Accel. Spectrometers, Detect. Assoc. Equip. 603 (2009)

10. V.M. Aulchenko, O.V. Evdokov, V.D. Kutovenko, B.Y. Pirogov, M.R. Sharafutdinov, V.M. Titov, B.P. Tolochko, A.V. Vasiljev, I.A. Zhogin, V.V. Zhulanov, Nucl. Instruments Methods Phys. Res. Sect. A Accel. Spectrometers, Detect. Assoc. Equip. 603 (2009)

11. G. Pérez, J.M. Sanz, Thin Solid Films. 416 (2002)

12. E.A. Baranov, A. O. Zamchiy, and S.Ya. Khmel, Technical Physics Letters 41 (2015)

13. M. van Sebille, A. Fusi, L. Xie, H. Ali, R.A.C.M.M. van Swaaij, K. Leifer, M. Zeman Nanotechnology. 27 (2016)

14. A.O. Zamchiy, E.A. Baranov, I.E. Merkulova, V.A. Volodin, M.R. Sharafutdinov, and S.Ya. Khmel, Vacuum 152 (2018)

15. E.A. Baranov, S.Y. Khmel, A.O. Zamchiy, I.V. Cheskovskaya, M.R. Sharafutdinov, Can. J. Phys. 92 (2014) 